\title{
A DISTRIBUTION NETWORK DESIGN FOR FAST-MOVING CONSUMER GOODS
}

\author{
O. S. Okunade ${ }^{1, *}$ and S. A. Daodu² \\ 1, 2, Dept of Industrial and Production Engineering, Univ. OF IBAdAN, IBAdan, OYo State, NIGERIA \\ 1, FACULTY OF BIO-ECONOMY DEVELOPMENT, VYTAUTAS MAGNUS UNIVERSITY, KAUNAS, LITHUANIA \\ Email addresses: ${ }^{1}$ os.okunade@ui.edu.ng, ${ }^{2}$ olanbiodun@gmail.com
}

\begin{abstract}
A distribution network design of fast-moving consumer goods ensures distribution of products in an effective manner by giving maximum customers' satisfaction and minimum distribution cost. The study evaluates the distribution through direct shipment and the use of intermediate shipment for distribution of products from plant to depots. A real-life case study in Southwestern Nigeria was defined and solved as a linear programming model to minimise total cost of distribution from plant to the depots with consideration of four routing options. The results show that distribution through intermediaries gives a better solution than routing option with direct shipment. The best routing option with intermediate points when compared with the routing option with direct shipment gives a savings of 1,819,490.00 Naira which translates to $13.46 \%$ cost savings. The study shows that the location of intermediaries is a key decision in distribution network design and that the intermediaries add value to the distribution networks in supply chain.
\end{abstract}

Keywords; Distribution network; Supply chain design; Fast-moving consumer goods; Linear programming.

\section{INTRODUCTION}

Supply chain design has been the concern of all organisations in achieving their set goals and also to remain competitive in the market. Its impact on the entire supply chain is huge because it provides a framework for operational and tactical supply chain [1]. Supply chain network design is important in the operations of fast-moving consumer goods companies. It ensures global competition, improved customer service as well as reduction of cost and waste [2].

A typical supply chain comprises customers, distribution centres, manufacturing plants and suppliers. These echelons of supply chain are confronted with challenges of location, allocation and distribution which involves making strategic, tactical and operational decisions. These are all challenges of supply chain network design. Effectiveness and efficiency of supply chain management are premised on the design of supply chain network.
Lemmens et. al. [3] argues that one of the factors that increase the complexity of supply chain network design is the integration of decision levels such as operational, tactical and strategic decision levels. This view is buttressed by [4] who asserts that the interaction and integration of these three decision levels is prerequisite for the design of competitive global supply chain. Supply chain network design models are classified into location-allocation, inventory-location and production-distribution models.

Production and distribution are two core areas of supply chain and their optimization is essential for improved performances. Production planning has to do with decision on labour requirement for production, types of production and production capacity. Distribution has to do with decision to determine the facilities that will cater for all requirements of its market. [5-6] identify distribution network design as one of the most important

* Corresponding author, tel: +234-807-977- 3067 
problems in supply chain management. Distribution is the key driver in the overall profitability of an organisation because of its effect on customers' satisfaction and supply chain cost. It involves location of manufacturing plant, distribution centres and helps in getting the best strategy from distribution of products.

Distribution refers to the movement and storage of products between different stages and every pair of supply chain stage has a distribution network. Raw materials are shipped to manufacturers from the suppliers while finished goods are shipped from the manufacturer to the distribution centres and then to the customers [7]. Distribution network design in supply chain helps in determining the least cost in the distribution of products (which could be raw materials, semi-finished goods or finished goods) between echelon of supply chain such that demand at warehouses and capacity at the plants are satisfied. Chopra in [8] gives two key decisions of distribution network design as shipment of product directly to customers and flow of product through the intermediate location. Based on these key decisions, the author gave six classifications for distribution network design.

The study compares the two decisions of distribution network design to evaluate the shipment of fastmoving consumer goods from the manufacturing plant to the depots. This study evaluates direct shipment of products to the distribution centres and use of the intermediate shipment for distribution of products from plant to depots and to determine the best alternative based on its performance in terms of the cost. Also, literature establishes that the transportation cost of direct shipment and shipment with intermediate nodes is high [7-8]. This study will help in establishing which of the design alternative is better in terms of transportation cost. This paper is structured as follows: Review of literature is outlined in Section 2. Section 3 states the methodology deployed in the case investigation, its problem formulation and solution procedure. Section 4 gives the results of study and discusses it. The conclusion of the study is outlined in section 5 .

\section{LITERATURE REVIEW}

Fast-moving consumer goods (FMCGs) are products that are consumed within a short period and are quickly replaced. It has a large market because it is highly consumed on daily basis. FMCGs require an efficient supply chain to drive its distribution operations thus ensuring minimised cost of distribution operations as well as maximised customers' satisfaction [9].

The effect of distribution process on supply chain cost and customer satisfaction is huge. This makes the distribution process a crucial decision for supply chain management. Therefore, optimum distribution network design helps organisations in minimisation of delivery cost and maximisation of customers satisfaction [10]. Distribution network design helps in determining simultaneously the best location for plant and distribution centre as well as the best distribution strategy to be employed [11-12].

Chopra in [8] provides a framework for evaluation of distribution network design in supply chain which considers factors that affect and influence choices of distribution, advantages and limitation of several choices of distribution. Distribution network design problem in supply chain is a strategic decision problem and several studies have addressed the problem.

Simulation of the physical and data flows in supply chain were modelled to maximise the efficiency of supply chain network. Software architecture was developed to model and simulate the flow of materials, data and decisions and the interconnections between them [13]. Complex network problem was studied as case studies by Ambrosino and Grazia-Scutellà [14] and mathematical programming was formulated for the identified problems.

Distribution network problem was formulated as mixed-integer programming and solved by heuristics based on Lagrangean relaxation [11]. The authors in [15] integrated inventory, transportation and facility location decision into distribution network design to minimise the expected total cost which includes the cost of inventory, transportation and facility set-up. Distribution networks behaviour was simulated by formulating a two-stage bi-level programming which was solved by hybrid metaheuristics [16].

Golmohammadi, et. al. [6] provide a unified model for distribution network design which defines the numbers, location and capacities of plant and distribution as decision variable and it simultaneously optimises the distribution of products from plants to distribution centres and from distribution centres to customers. The problem was formulated as mixedinteger programming and was solved as a two-phase heuristic. 
A mixed-integer linear programming model was used to optimise the production and distribution network with consideration of financial and operational constraints [17]. Supply chain production and distribution models were reviewed by Mula, et.al.[18] who grouped the literature into supply chain structure, decision level, modelling approach, purpose, shared information, limitations, novelty and application.

The distribution network design of Agric-food supply chain and a case study of the distribution of chicken in one city in Algeria was considered by Boudahri, et. al. [19]. The study finds the centroid of set of retailers and the location and allocation of slaughterhouses such that the total cost of logistics is minimised while the transportation and slaughterhouses capacities constraints are satisfied. The problem was formulated as capacitated centred clustering and locationallocation problems.

Two-stage location-routing-inventory problem with time windows was proposed for food distribution network. The food distribution network problem is formulated as a mixed-integer programming model and hybrid heuristics is proposed as a solution approach[20].

Relief distribution problem was formulated as multiobjective mixed integer nonlinear programming for maximising the lowest perceived satisfaction of victims and minimising the largest deviation of perceived satisfaction of victims which alleviates the suffering of the victims. Genetic algorithm was used to solve the relief distribution problem[21].

Multi product distribution network was modelled as mixed-integer programming. It was defined and solved as pharmaceutical distribution network problem [12]. Multi-product, multi-echelon problem which considers of operation of cross-docking was formulated as a mixed-integer programming model and simulated annealing, a practical and robust method was used to solve it [22].

Kumar, et. al. [23] quantifies the trade-off in inventory cost minimisation and customer satisfaction maximisation and assessment of supply chain performance metrics. The authors provided dynamic decision support which enables the effectiveness of supply design and 3-stage analytical approach was used for multi-echelon distribution networks. The authors in [24] assess the feasibility of integrating operations of three echelon of supply chain using decision tree and simulation approach.
Distribution network of multi-commodity incorporates customers' demands that are price sensitive. This problem was modelled as mixed-integer nonlinear programming and solved by Lagrangian relaxation algorithm [25]. The design of two-echelon distribution network with uncertainty in customers' demand was considered by [26] and the authors presented a detailed method to solve the stochastic multi-period two-echelon distribution network design problem.

A multichannel distribution supply chain network model was proposed for omnichannel distribution environment which on comparison with traditional supply chain network achieves savings in cost, provides better customer services and it is sustainable [27].

The study develops supply chain distribution network design model which incorporate decision-makers' imprecise goal aspiration levels and uncertainty in demand through a fuzzy goal programming approach.[28]. Other studies also use fuzzy programming approach for distribution network in supply chain[29-34].

It can be seen that mixed-integer programming was used in most of these studies while others differ in the formulation approach by using fuzzy programming in addressing the imprecise nature of demand. One of the key challenges of supply network design, as identified by [1], is the decision on using direct distribution, an intermediate distribution or a hybrid of the two. This study formulates the distribution network design as a linear programming model for evaluation of intermediaries and direct shipment alternatives

\section{METHODOLOGY}

This section presents the case investigated, the theoretical framework for the formulation of case study and solution procedure.

\subsection{Case study and Data collection}

A fast-moving consumer goods (FMCGs) company in South-Western Nigeria was visited and interview of stakeholders of the operations of the FMCG products from plant to the distribution centres called depots were carried out. The FMCGs company is into production and distribution of beverages. It has 5 products in polyethylene terephthalate (PET) and glass bottles available in $35 \mathrm{cl}, 50 \mathrm{cl}$ and 1 litre. The plant has been in operation for close to four decades. The plant distributes its products to nine depots 
across some areas in Southwestern Nigeria. The company distributes the products directly to various depots without transshipment points. The products are manufactured in the plant based on demand from the depots. The products are shipped by vehicle to meet the requirement at the depots. This study evaluates the alternative of shipping through intermediaries and compares it with direct shipment to all depots.

Data were collected through historical records and interview of staff, the average monthly demand for each depot was obtained, the total cost of transporting products to each depot was determined based on the actual distance of each depot to the plant and the cost of fuel per litre for covering the respective distances to each depot per truck. Table 1 gives the location and distance in kilometres $(\mathrm{km})$ of respective depots from the plant. The locations are represented with alphabets. The cost of diesel per litre is 225 Naira. Other data are summarized in Tables 2 and 3.

\subsection{Case study problem formulation}

Introduction of intermediaries defines the distribution network design as a transshipment problem which is a generalization of transportation problem that allows distribution of goods moves through the intermediate nodes before reaching the final destination and also, transshipment is a special case of minimum cost flow problem. The problem formulation is based on the assumption of traditional transportation problem and formulated as linear programming and the notation used in defining the mathematical model is stated as follows:

I: set of plants $i \in I$ for $i=1,2, \ldots, r$

$\mathrm{J}$ : set of intermediate points $\mathrm{j} \in \mathrm{J}$ for $\mathrm{j}=1,2, \ldots, \mathrm{S}$

$K$ : set of depots $k \in K$ for $k=1,2, \ldots, t$

$A_{i}$ : quantity of product available for shipment in plant i

$B_{k}$ : quantity demanded at depot $k$

$D_{j}$ : capacity of intermediate point $j$

$c_{i j}$ : cost of shipping unit of product from plant $i$ to intermediate point $j$

$c_{\mathrm{jk}}$ : cost of shipping unit of product from intermediate point $\mathrm{j}$ to depot $\mathrm{k}$

The decision variables are:

$x_{i j}$ : amount of product shipped from plant $i$ to intermediate point $\mathrm{j}$

$\mathrm{X}_{\mathrm{jk}}$ : amount of product from shipped from intermediate point $\mathrm{j}$ to depot $\mathrm{k}$

The Objective function is defined as follows:
The total cost of shipping from plant $i$ to all intermediate points is given as:

$$
C\left(s, x_{i j}\right)=\sum_{j=1}^{s} c_{i j}
$$

The total cost of shipping from intermediate point $j$ to all depots is expressed as:

$$
C\left(t, x_{j k}\right)=\sum_{k=1}^{t} c_{j k}
$$

The total cost of shipping from all plants to all depots is given as:

$$
Z=\sum_{i=1}^{r} \sum_{j=1}^{s} c_{i j} x_{i j}+\sum_{j=1}^{s} \sum_{k=1}^{t} c_{j k} x_{j k}
$$

The constraints are defined as follows:

$$
\begin{gathered}
\sum_{i=1}^{r} x_{i j}-\sum_{k=1}^{t} x_{j k}=0 \\
\sum_{j=1}^{s} x_{i j} \leq A_{i} \\
\sum_{j=1}^{s} x_{j k}=B_{k} \\
x_{i j} \geq 0 \\
x_{j k} \geq 0
\end{gathered}
$$

The mathematical model for distribution network design of FMCGs is:

Minimise $\mathrm{Z}=\sum_{i=1}^{r} \sum_{j=1}^{S} c_{i j} x_{i j}+\sum_{j=1}^{s} \sum_{k=1}^{t} c_{j k} x_{j k}$

Subject to:

$$
\begin{aligned}
& \sum_{i=1}^{r} x_{i j}-\sum_{k=1}^{t} x_{j k}=0 \\
& \sum_{j=1}^{s} x_{i j} \leq A_{i} \\
& \sum_{j=1}^{s} x_{j k}=B_{k} \\
& x_{i j} \geq 0 \\
& x_{j k} \geq 0
\end{aligned}
$$

The objective function is to minimise the total cost of shipping from plant to the depots. (4) implies that the quantity of products delivered to each intermediate point is equal to the quantity of products shipped from that intermediate points to the depots. The supply and demand constraints are (5) and (6) respectively while (7) and (8) give the non-negativity constraints.

\subsection{Problem solution procedures}

The distribution network design problem for FMCGs is solved by the procedure as adapted from the traditional transportation problem: 
- Identify the supply, transshipment and demand points.

- Determine the value of all problem parameters.

- Set-up the transshipment matrix or a network diagram for the problem.

- Formulate the linear programming model for the matrix or network diagram.

- Solve the cost minimizing distribution network design problem for FMCGs as linear programming problem.

\section{RESULTS AND DISCUSSION}

The following routing options were considered for distribution network design problem of FMCGs. The first routing option ship directly from plant to all depots while other routing options consider a minimum of three intermediate points.

The locations of intermediates points are based on the closeness to the plant as well as other demand points. The study does not exhaust all alternatives with respect to the selection criterion. Each routing option has intermediate points that have enough capacity to store product which will be conveyed to the destination points. Figures 1 to 4 gives the network diagram of the routing options. LINGO was used to solve the distribution network design problem of FMCGs.

Table 1: Location and Distances of Depots from Plant

\begin{tabular}{llll}
\hline \multirow{2}{*}{ SN } & \multicolumn{3}{l}{ Location and Distance of Depots from Plant } \\
\cline { 2 - 4 } & Node & Location & Distance $(\mathrm{km})$ \\
\hline 1 & 1 & A & - \\
2 & 2 & B & 152 \\
3 & 3 & C & 151 \\
4 & 4 & D & 134 \\
5 & 5 & E & 122 \\
6 & 6 & F & 110 \\
7 & 7 & G & 85 \\
8 & 8 & H & 123 \\
9 & 9 & I & 86 \\
10 & 10 & J & 103 \\
\hline
\end{tabular}

Table 2: Transportation Cost and Demand of Depots Relative to Plant

\begin{tabular}{lllll}
\hline $\begin{array}{l}\text { Nod } \\
\mathrm{e}\end{array}$ & $\begin{array}{l}\text { Locatio } \\
\mathrm{n}\end{array}$ & $\begin{array}{l}\text { Transportatio } \\
\mathrm{n} \operatorname{cost}(\mathrm{A})\end{array}$ & $\begin{array}{l}\text { Unit } \\
\text { Transportatio } \\
\mathrm{n} \operatorname{cost}(\mathrm{A})\end{array}$ & $\begin{array}{l}\text { Deman } \\
\mathrm{d}\end{array}$ \\
\hline 1 & $\mathrm{~A}$ & - & - & - \\
2 & $\mathrm{~B}$ & 6200 & 62 & 24430 \\
3 & $\mathrm{C}$ & 6200 & 62 & 42250 \\
4 & $\mathrm{D}$ & 5500 & 55 & 39075 \\
5 & $\mathrm{E}$ & 5000 & 50 & 45738 \\
6 & $\mathrm{~F}$ & 4500 & 45 & 25973 \\
7 & $\mathrm{G}$ & 3500 & 35 & 65007 \\
8 & $\mathrm{H}$ & 5000 & 50 & 18697 \\
9 & $\mathrm{I}$ & 3500 & 35 & 16253 \\
10 & $\mathrm{~J}$ & 4200 & 42 & 11093 \\
\hline
\end{tabular}

Table 3: Relative costs of transportation between intermediate locations to the destinations

\begin{tabular}{|c|c|c|c|c|c|c|c|c|c|c|c|}
\hline \multirow{2}{*}{\multicolumn{2}{|c|}{${ }_{i}{ }^{j}$}} & 1 & 2 & 3 & 4 & 5 & 6 & 7 & 8 & 9 & 10 \\
\hline & & $A$ & $B$ & C & $\mathrm{D}$ & $E$ & $\mathrm{~F}$ & $\mathrm{G}$ & $\mathrm{H}$ & I & $\mathrm{J}$ \\
\hline 1 & $A$ & & 62 & 62 & 55 & 50 & 45 & 35 & 50 & 35 & 42 \\
\hline 7 & G & & & 105 & & 47 & 50 & & & 43 & \\
\hline 8 & $\mathrm{H}$ & & & 27 & 22 & & & & & & \\
\hline 9 & $\mathrm{I}$ & & & 60 & & & & & 35 & & 25 \\
\hline 10 & J & & 30 & & 34 & & & & & & \\
\hline
\end{tabular}

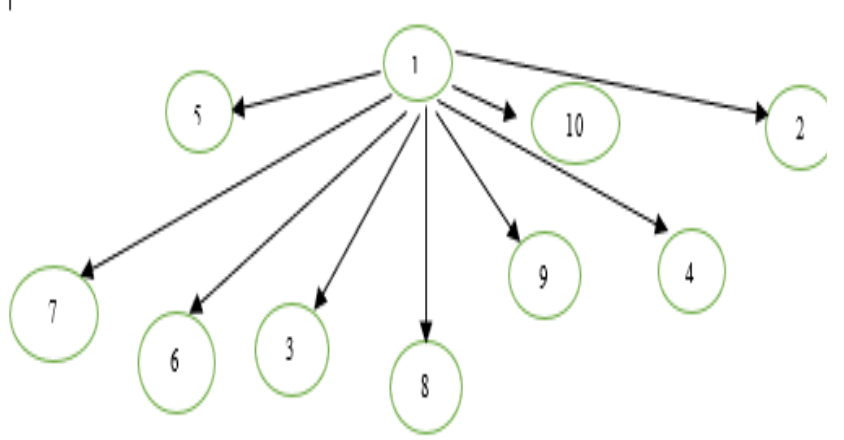

Fig.1: Network diagram of routing option 1

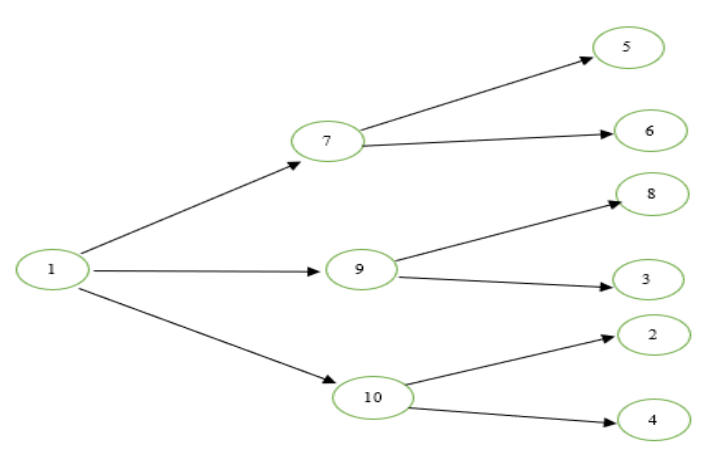

Fig.2: Network diagram of routing option 2 


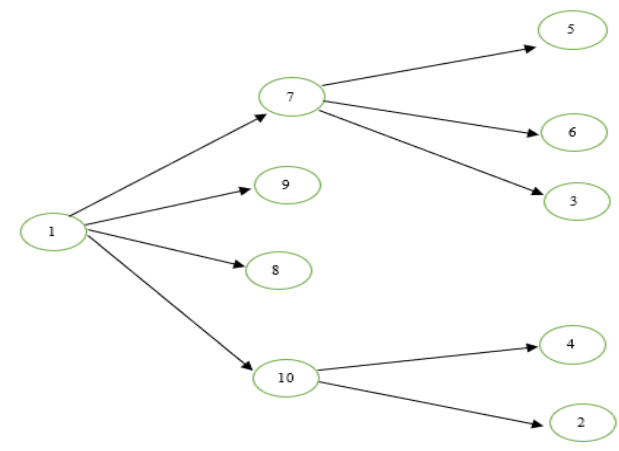

Fig. 3: Network diagram of routing option 3

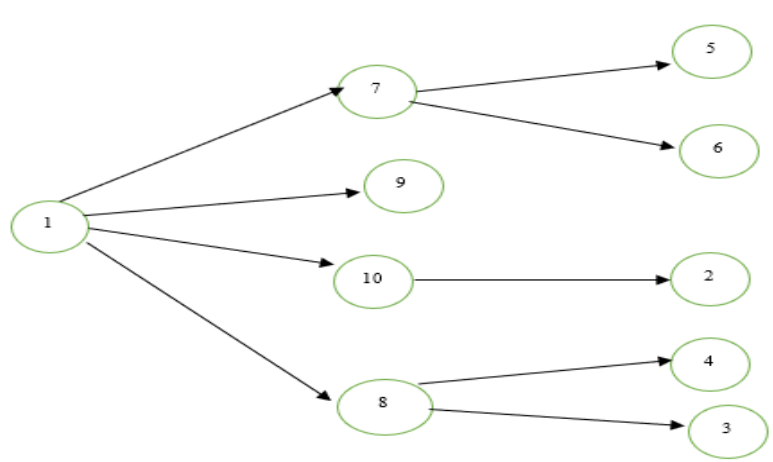

Fig. 4: Network diagram of routing option 4

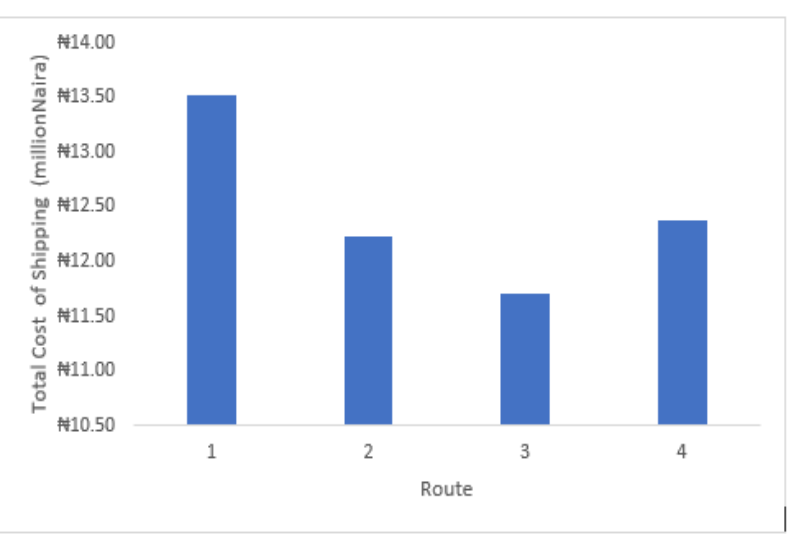

Fig. 5: Chart showing the total cost of shipping for defined routing option

The total cost of distribution for routing options 1,2 , 3 , and 4 are $\# 13,517,920.00, \# 12,230,680.00, A$ $11,698,430.00$ and $\# 12,381.050 .00$ respectively. It was observed from the result that routing option 1 which involves direct shipment to the depots has a total of $1.352 \times 10^{7}$ Naira. Routing option 2 has three intermediates points at depot $G, I$ and $J$ which distribute to depots $B, C, D, E, F$, and $H$ as depicted in Figure 2 gives a total of $1.223 \times 10^{7}$ Naira. The total transportation cost of routing option 4 which has direct shipment to depot I and three intermediate points at depots $G, H$, and J shipping products to the rest depot as shown in Figure 4 is $1.238 \times 10^{7}$ Naira. Routing option 3 has three intermediate points G, I, and $\mathrm{J}$ which distributes products to $\mathrm{B}, \mathrm{C}, \mathrm{D}, \mathrm{E}, \mathrm{F}$, and $\mathrm{H}$ as illustrated in Figure 3 gives the best solution with a total cost of $1.169 \times 10^{7}$ Naira.

It can be seen that routing option 2,3 , and 4 which has intermediate points gives a lower cost compared to routing option 1 . Distribution network design with the incorporation of intermediate points gives a better result as compared with the direct shipment for the routing options considered as shown in Figure 5. Also, the best routing option when compared to the existing distribution network approach which is directly shipped products to all depots gives a savings of $1,819,490.00$ Naira which translates to $13.46 \%$ cost savings. Routing option 2, 3 and 4 consider the distribution of products through intermediate points and the differences in their results suggest that location decision is of prime importance in supply chain distribution network design. The results suggest that introduction of intermediate points can provide a cost saving for a logistic system of fast-moving consumer goods. The introduction of intermediate point offers several decision alternatives for accommodation of changes in the shipment of goods in conformity with the global and modern practices. It can also help in enhancing flow of goods in case of emergencies and peak seasons.

\section{CONCLUSION}

The study addresses the distribution network design problem of fast-moving consumer goods with one central manufacturing plant and multi-distribution centres. The study proposes evaluation of distribution network design with the incorporation of intermediaries and direct shipment distribution network design. The problem was modelled and solved as a linear programming model by minimising the total cost of distributing the product. LINGO was used in solving the distribution network design problem of FMCGs. The study shows that distribution network design with intermediaries gives a better result than that of direct shipment. Also, the location(s) of the intermediate point(s) is critical in that it ensures the total cost of distribution is minimised. These results support the assertion of Chopra [8] that intermediaries such as transshipment points add value to distribution network in supply chain. 


\section{ACKNOWLEDGEMENT}

Vytautas Magnus University, Kaunas, Lithuania is acknowledged for the library resources used for this article.

\section{CORRESPONDENCE}

All correspondence should be sent to O.S Okunade, Department of Industrial and Production Engineering, University of Ibadan, Nigeria, e-mail: os.okunade@ui.edu.ng.

\section{REFERENCES}

[1] Sabri, E. H., and Salim, N. S. Lean and agile value chain management: a guide to the next level of improvement, J. Ross Publishing, Florida, 2010.

[2] Ogunlela, G.O. "Integrated Supply Chain Management in the Fast-Moving Consumer Goods Manufacturing Industry: A Review." Journal of Economics and Behavioral Studies, Vol.10, Number 4 (J), 2018, pp 213220.

[3] Lemmens, S., Decouttere, C., Vandaele, N. and Bernuzzi, M. "Integrated Supply Chain Network Design Models for Vaccines: A Literature Review", Faculty of Economics and Business Research Report KBI_1414. 2014

[4] Schmidt, G. and Wilhelm,W.E. "Strategic, tactical and operational decisions in multi-national logistics networks: A review and discussion of modelling issues", International Journal of Production Research, Vol.38, Number 7, 2000, pp 1501-1523.

[5] Fahimnia, B., Farahani, R.Z., Marian, R. and Luong, L."A review and critique on integrated production-distribution planning models and techniques. Journal of Manufacturing Sysem, Vol.32, Number 1, 2013, pp 1-19.

[6] Golmohammadi V, Afshari $H$, Hasanzadeh A and Rahimi M. "A heuristic approach for designing a distribution network in a supply chain system", African Journal of Business Management, Vol.4, Number 3, 2010, pp 308-311.

[7] Chopra,S. and Meindl, P. Supply Chain Management: Strategy, Planning and Operations,3rd Edition, Pearson Prentice Hall, Upper Saddle River, NewJersey, 2007

[8] Chopra, S."Designing the distribution network in a supply chain". Transportation Research Part E Logistics and Transportation Review, Vol.39, Number 2, 2003, pp123-140.
[9] Leahy, R. "Relationships in fast-moving consumer goods markets", European Journal of Marketing Vol. 4, 2011, pp 651-672.

[10] Ceyhun, G.C."An Assessment for Classification of Distribution Network Design",in: Handbook of Research on the Applications of International Transportation and Logistics for World Trade. IGI Global; 2020

[11] Amiri, A. "Designing a distribution network in a supply chain system: Formulation and efficient solution procedure", European Journal of Operational Research,Vol. 171, Number 2, 2006, pp 567-576.

[12] Rabbani, M., Tavakkoli-Moghaddam,R. and Parsa, H. "A new mathematical model for a distribution network problem in a multi-product supply chain system: A real-case study", International Journal of Manufacturing Technology and Management, Vol. 15, Number 1, 2008, pp1-11.

[13] Godding, G.W.Sarjoughian,H.S. and Kempf, K.G. " Supply chain and distribution network: semiconductor supply network simulation", $35^{\text {th }}$ Conference onWinter Simulation driving innovation, December 7, 2003.

[14] Ambrosino,D. and Grazia Scutellà, M. "Distribution network design: New problems and related models", European Journal of Operational Research, Vol.165, Number 3,2005, pp 610-624.

[15] Shu, J.and Sun, J. "Designing the distribution network for an integrated supply chain", Journal of Industrial and Management Optimization,Vol. 2, Number 3, 2006, pp 339349.

[16] Hajiaghaei-Keshteli, M. and Fathollahi-Fard, A. $M$. "A set of efficient heuristics and metaheuristics to solve a two-stage stochastic bi-level decision-making model for the distribution network problem", Computer \& Industrial Engineering, Vol. 123, 2018, pp 378395.

[17] Tsiakis, P. and Papageorgiou, L.G." Optimal production allocation and distribution supply chain networks", International Journal of Production Economics, Vol. 111, Number 2, 2008, pp 468-483.

[18] Mula, J., Peidro, D., Díaz-Madroñero, M. and Vicens, E."Mathematical programming models for supply chain production and transport planning", European Journal of Operational Ressearch,Vol. 204, Number 3, 2010, pp377390. 
[19] Boudahri, J.F. Sari, Z. Maliki, F. and Bennekrouf, M. "Design and optimization of the supply chain of agri-foods: Application distribution network of chicken meat, 2011 International Conference on Communications, Computing and Control Applications, IEEE, Hammanet, Tunisia, March 3-4, 2011.

[20] Chao, C. Zhihui, T. and Baozhen, Y. "Optimization of two-stage location-routinginventory problem with time-windows in food distribution network", Annals of Operations Research, Vol. 273, Numbers 1-2, 2019, pp 111-134.

[21] Cao, C., Li, C., Yang, Q., Liu, Y.and Qu, T."A novel multi-objective programming model of relief distribution for sustainable disaster supply chain in large-scale natural disasters", Journal of Cleaner Production, Vol 174, 2018, pp 14221435.

[22] Jayaraman, V. and Ross, A. " A simulated annealing methodology to distribution network design and management", European Journal of Operational Research,Vol.144, Number 3, 2003, pp 629-645.

[23] Kumar, S., McCreary, M. L.and Nottestad, D. A."Quantifying supply chain trade-offs using six sigma, simulation, and designed experiments to develop a flexible distribution network", Quality Engineering, Vol. 23, Number 2, 2011, pp 180203.

[24] Hernandez, M.C., Rosas, L.V., Mantilla, R.R., Martínez, G.E. and Romero, V.V."Supply chain cooperation by agreed reduction of behaviour variability: A simulation-based study", Engineering, Technology \& Applied Science Research, Vol 7. Number 2, 2016, pp.15461551.

[25]Ahmadi-Javid, A. and Hoseinpour, P."Incorporating location, inventory and price decisions into a supply chain distribution network design problem", Computers \& Operations Research, Vol.56, 2015, pp 110119.

[26] Ben Mohamed, I., Klibi, W. and Vanderbeck, F."Designing a two-echelon distribution network under demand uncertainty", European Journal of Operational Research, Vol. 280, Number 1, 2020, pp 102-123.
[27] V.S.,Tripathi, S. and Singh, A. R."Bi-objective optimization for sustainable supply chain network design in omnichannel", Journal of Manufacturing Technology Management, Vol.30, Number 6, 2019, pp 972-986.

[28] Selim, H. and Ozkarahan,I. "Application of fuzzy multi-objective programming approach to supply chain distribution network design problem", Mexican International Conference on Artificial Intelligence, Apizaco, Mexico,November 13-17, 2006

[29] Costantino, N., Dotoli, M., Falagario, M., Fanti, M.P. Mangini, A.M., Sciancalepore, F. and Ukovich, W." A fuzzy programming approach for the strategic design of distribution networks", 2011 IEEE International Conference on Automation Science and Engineering, Trieste, Italy, August 24-27, 2011

[30] Bilgen,B. "Application of fuzzy mathematical programming approach to the production allocation and distribution supply chain network problem", Expert Systems with Applications, Vol. 37, Number 6, 2010, pp 4488-4495.

[31] Paksoy, T., Pehlivan, N.Y.and Özceylan, E. "Application of fuzzy optimization to a supply chain network design: a case study of an edible vegetable oils manufacturer", Applied Mathematical Modelling, Vol. 36, Number 6, 2012, pp. 2762-2776.

[32] Wu, G.H., Chang, C.K. and Hsu, L.M."Comparisons of interactive fuzzy programming approaches for closed-loop supply chain network design under uncertainty", Computers and Industrial Engineering, Vol. 125,2018, pp 500-513.

[33] Darbari, J.D., Kannan, D., Agarwal, V. and Jha, P.C. "Fuzzy criteria programming approach for optimising the TBL performance of closed loop supply chain network design problem", Annals of Operations Research, Vol. 273, Numbers 12, 2019, pp 693-738.

[34] Gholipour, S., Ashoftehfard, A. and Mina, H. "Green supply chain network design considering inventory-location-routing problem: a fuzzy solution approach", International Journal of Logistics Systems and Management, Vol.35, Number 4, 2020, pp 436452. 